\title{
Islam and End-of-Life Practices in Organ Donation for Transplantation: New Questions and Serious Sociocultural Consequences
}

\author{
Mohamed Y. Rady $\cdot$ Joseph L. Verheijde $\cdot$ Muna S. Ali
}

Advances in knowledge about human biological processes bring into question whether either brain (heart-beating) or circulatory (non-heartbeating) criteria of death ensure that donors are really dead before organ procurement. The utility of conflating the "prognosis" (incipiently dying or destined to die) with the "diagnosis" of death (really dead) to justify organ donation has been morally defended in both the medical and the ethics literature. Major religions emphasize the sanctity of human life but permit organ donation if it is performed after death. Thus, the moral justification of end-of-life practices in organ donation poses serious ethical and religious challenges. Legislation has been introduced in several countries, including the United States, to permit the administration of life support systems for organ preservation without prior consent for organ donation. Such administration of life support systems for organ preservation interrupts traditional Islamic practices about the care of the dying and the deceased.

We conclude that: 1) many practical aspects of end-of-life organ donation conflict with the Islamic faith's core principles of care for the dying and their families; 2) defining the societal role of transplantation medicine is not uniquely a matter of accounting for technical capabilities and expertise, but must include the recognition of cultural, social, and religious values that constitute morality and guide best scientific evidence; 3) Muslim scholars should critically evaluate new evidence about end-of-life practices in organ donation, their effects on the care of terminally ill patients and their families

\footnotetext{
Mohamed Y. Rady, MD, Ph.D., FRCS (Eng.), FRCP (UK), FCCM, Professor of Medicine and consultant in Critical Care Medicine at Mayo Clinic Hospital in Phoenix, 5777 East Mayo Boulevard, Phoenix, Arizona, USA, 85054; email: Rady.Mohamed@mayo.edu.
}

Joseph L. Verheijde, MBA, Ph.D., Associate Professor of Biomedical Ethics, Mayo Clinic College of Medicine, 5777 East Mayo Boulevard, Phoenix, Arizona, USA, 85054; email: jverheijde@mayo.edu.

Muna S. Ali is a doctoral student in Sociocultural Anthropology at Arizona State University; email: muna.ali@asu.edu. 
and the consequences on the cultures of Muslim communities worldwide.

\section{Introduction}

Islam is a monotheistic religion established in 610 A.D. by the Prophet Muhammad. Like Judaism and Christianity, it is an Abrahamic faith. Islam is a world-wide religion of 1.3 billion Muslims (Beliefnet.com, 2008). There is no typical Muslim: $40 \%$ are Asian (e.g., from India, Pakistan, Afghanistan, Indonesia, Malaysia, China, and the Philippines); $30 \%$ are from sub-Saharan Africa; $20 \%$ are from the Middle East; $3 \%$ are native to Europe; and $1 \%$ are native to the Americas (Beliefnet.com, 2008). In the United States alone, there are about 5 million Muslims: 30\% black, 27\% white (including Europeans, Anglo-Americans, Arabs, and Iranians), and 33\% Southeast Asian (Hedayat, 2006).

There is no papacy in Islam. Legal opinions (i.e., fatwas) may be sought about contentious or contemporary issues from Muslim scholars, who are acknowledged experts in matters of Islamic law and ethics. The primary source of references for reaching a fatwa is The Quran (see www.quranexplorer.com/Quran/). The next most valuable source is The Sunnah, which describes the tradition of the Prophet Muhammad: what he said, what he did, what he saw and approved during his lifetime. If neither of these resources contains a reference to the issue in question, the scholars exercise Ijtihad, the practice of rendering opinions based on reasoning or original analysis following the methodology and general principles in usulal-figh (i.e., Islamic jurisprudence) (Gatrad \& Sheikh, 2001; Padela, 2007). Several general principles guide Muslim scholars in issuing opinions on the moral status, values, and consequences of certain actions (Table 1) (Al-Allaf, 2003; Padela, 2007). The Quran and the Sunnah do not explicitly address organ donation and transplantation because these are historic precursors to transplantation medicine (Al-Khader, Shaheen \& Al-Jondeby, 2003; ElShahat, 1999). Therefore, opinions on this practice are issued by Ijtihad of Muslim scholars (Gatrad \& Sheikh, 2001). Organ donation is permitted by the Islamic principles that need and necessity are equivalent and that necessity allows even prohibited matters (Akrami et al., 2004; Al-Mousawi, Hamed \& Al-Matouk, 1997; El-Shahat, 1999). On that basis, the need for organ transplantation has been interpreted as a necessity, which permits a traditionally prohibited action (i.e., the violation of the sanctity of the body for organ donation conditional upon no harm befalling the donor). Organ donation for transplantation is a medical field that has witnessed dramatic changes in practice during the past four decades. Advances in medical knowledge and technology have required Muslim scholars periodically to 
consult medical scientists to better understand the science behind such changes in practice and the relevant issues as they pertain to Islamic opinions (Gatrad \& Sheikh, 2001; Padela, 2007). Islamic opinions on a certain medical practice may be revised from time to time as advances in medical technology may generate new questions.

In this article, we outline past and present practices and future trends in end-of-life organ donation. We describe the current understanding of human biological processes in the dying phase to refute the current medical stance that donors are really dead before organ procurement, when death is declared by either brain or circulatory criteria. We describe organ preservation procedures, including the use of life support systems for organ preservation before procurement, in relation to traditional Islamic practices for the care of the dying and the deceased. Finally, we outline legislative revisions in the United States and other countries that allow the administration of life support systems to dying patients for the purpose of organ preservation without their prior consent for donation.

\section{Practice Changes in Organ Procurement}

\section{Historical Perspective}

The practice of organ donation for transplantation has witnessed major changes over the past four decades (Kauffman et al., 2007; Snoeijs et al., 2007). The practice criteria required to procure organs for transplantation have been significantly abbreviated to expand the pool of eligible organ donors at the end of life (Figure 1). Table 2 describes the timeline of biological processes and natural events (E) of the dying phase in human beings. In July 1967, Dr. Starzl transplanted a human liver from a donor who met the criteria of brain death and was disconnected from mechanical ventilation (Starzl et al., 1968). Organ donation procedures were initiated after cardiac arrest and cessation of electric activity on the electrocardiogram (Figure 1). That same year, in December 1967, Dr. Barnard transplanted a human heart from a donor who had been declared "brain dead" after a lethal traumatic brain injury (Barnard, 1967). The donor was disconnected from mechanical ventilation, and donation procedures were initiated after cardiac arrest and cessation of electrical activity on the electrocardiogram. The donor was placed on a cardiopulmonary bypass machine to cool the donor body and procure the heart. In both landmark transplant cases, the determination of death was based on a combination of brain and cardiac criteria

The following year (1968), an ad hoc committee of Harvard Medical 
School that had been convened to examine the definition of brain death published a report on persistent (irreversible) coma with apnea to establish consensus criteria for determining death in patients with beating hearts who were on mechanical ventilation in the United States (Beecher, 1968). The initial purpose of the brain-death criteria for a declaration of death was to permit physicians to withdraw artificial life support systems and withhold additional aggressive treatment. Also in the same year, the Uniform Anatomical Gift Act (UAGA) was drafted for legally permitting the donation and procurement of cadaveric tissue and organs for transplantation. The original UAGA was amended in 1987 and then again in 2006, with the latter version known as the Revised UAGA (National Conference of Commissioners on Uniform State Laws, 2006).

\section{Current Practice in Organ Procurement}

It is unknown exactly when U.S. clinical transplant programs started using brain criteria to declare death and recover organs in brain-death heartbeating organ donation (HBOD) rather than using the brain criteria of death to terminate life support systems leading to cardiac arrest and organ recovery in brain-death non-heart-beating organ donation (NHBOD) (Figure 1). Nevertheless, the Uniform Determination of Death Act (UDDA) became effective in 1981 and provided the legal permission to procure vital (heart and lungs) and non-vital organs (e.g., liver, kidneys, pancreas, and intestines) after a declaration of death by brain criteria in heart-beating donors (Figure 1) (National Conference of Commissioners on Uniform State Laws, 1981). The UDDA states: "An individual who has sustained either (1) irreversible cessation of circulatory and respiratory functions, or (2) irreversible cessation of all functions of the entire brain, including the brain stem, is dead. A determination of death must be made in accordance with accepted medical standards."

In 1992, the University of Pittsburgh Medical Center constituted a protocol to allow organ donation following the withdrawal of life support systems at the end of life in unsalvageable patients who did not meet brain criteria for a declaration of death (DeVita \& Snyder, 1993). The Pittsburgh protocol permitted organ procurement after 2 minutes of simultaneous loss of arterial pulse, apnea, and unconsciousness (with the presence of electrocardiographic cardiac activity at the moment of E2a [Table 2]). These three physical signs constituted the sole circulatory criterion to declare death in NHBOD (Figure 1). A similar protocol to procure organs from terminally ill patients who did not meet brain-death criteria and ultimately died of cardiac arrest after withdrawal of life support was also developed at the 
University Hospital Maastricht in Maastricht, the Netherlands (Snoeijs et al., 2007). The NHBOD protocol required patients to be moved to the operating room for preprocurement interventions before the withdrawal of life support systems. This protocol provided the template for the medical practice of NHBOD (later renamed "donation after cardiac death") in the United States and world-wide.

The U.S. Institute of Medicine published three reports in 1998, 2000 and 2006 in support of NHBOD as an ethically acceptable medical practice (Institute of Medicine, 1998; 2000; 2006). The 2006 report concurred with a previous National Conference on Organ Donation After Cardiac Death that was held on April 7 and 8, 2005, in Philadelphia under the auspices of the United Network for Organ Sharing (UNOS) and the Organ Procurement and Transplantation Network (OPTN) (Bernat et al., 2006). At that conference, the transplant community declared the ethical propriety of NHBOD on behalf of the U.S. medical community and the general public. The conference report launched a new era in organ donation, such that braindeath criteria were no longer the only criteria to procure organs for transplantation.

In July 2007, both UNOS and OPTN introduced new bylaws for NHBOD across the United States (UNOS, 2007). In Bylaws Appendix B Attachment III DCD (donation after cardiac death) Recovery Protocol Model Elements, the donor age range is expanded to include as young as newborns and with no upper age limit. Medical conditions suitable for donating organs include irrecoverable brain injury, spinal cord disease, musculoskeletal disorders, and end-stage pulmonary disease. The bylaws also introduce procedures such as the initiation of extracorporeal membrane oxygenation (i.e., cardiopulmonary bypass or use of artificial heart-lung machines) and bronchoscopy (i.e., tracheal intubation and lung insufflation) for organ preservation after declaring death using the circulatory criterion (Figure 2). Cardiopulmonary bypass machines can be used to maintain the artificial circulation of oxygenated blood as an interval extracorporeal support for organ retrieval in NHBOD (Figure 1) (UNOS, 2007). The mandatory two minutes in the Pittsburgh protocol has also been shortened to begin surgical organ procurement after 75 seconds of circulatory arrest in infants and children (Boucek et al., 2008). Donation-related procedures and abbreviation of the Pittsburgh protocol waiting time enable the procurement of vital organs (heart and lungs) and non-vital organs (e.g., liver, kidneys, pancreas, and intestines) in NHBOD for transplantation. 


\section{Future Practice Changes in Organ Procurement}

In September 2007, the President's Council on Bioethics debated whether the brain criteria for a declaration of death should be broadened because of the increased demand for transplantable organs (President's Council on Bioethics, 2007a). A broadening of the brain criteria for death was proposed that would include brain failure or dysfunction. The proposed definition can classify the irreversible cessation of higher brain function (or bilateral cerebral hemispheric function) with preserved brain-stem function as a criterion that would permit organ procurement. This definition can also apply to irrecoverable neurological conditions characterized by the loss of personhood (i.e., interaction, awareness, and communication with the external environment). This definition overlaps with those of other neurological conditions involving cognitive disabilities and altered consciousness but with preservation of brain-stem function such as persistent vegetative states, minimal consciousness states, and locked-in syndromes (Laureys, 2005). If these irrecoverable neurological conditions are to be reassigned under the umbrella of brain-death criteria for the purpose of organ donation, it is unclear how HBOD can be performed without concurrent administration of general anesthesia (Figure 1) (Rifkinson-Mann, 2003; Young and Matta, 2000). Indeed, transplant advocates have renewed their interest in permitting organ procurement from the terminally ill before death with adjunct administration of general anaesthesia (NEJM Perspective Round Table, 2008; Truog and Miller, 2008) and also from those requesting physician-assisted death (Detry et al., 2008).

\section{Ethical Considerations in Organ Procurement}

\section{Redefining Death: The Really Dead or Incipiently Dying Donor}

The separation between the incipiently dying and the really dead must be unequivocal and absolute in medical practice. A body of evidence suggests that organ donors who are declared dead either by brain or circulatory criteria may be not really dead but instead may be incipiently dying or destined to die (Joffe, 2007a; Shewmon, 1998; Truog, 2007; Veatch, 2008; Zamperetti, 2004). There is emerging scientific evidence that questions the validity of brain criteria for a declaration of biological or somatic death for the purpose of procuring vital and nonvital organs in HBOD (Karakatsanis, 2008; Truog, 2007; Zamperetti, 2004). The irreversible cessation of higher brain and brain-stem functions is not synonymous in human beings with the loss of somatic integrative unity or with the cessation of coordinated biological functions characteristic of living organisms (Joffe, 2007b; Maruya 
et al., 2008). The so-called brain-dead patient shares many features with the living patient. Patients declared brain dead are capable of somatic growth and development, reproduction, and function in non-vital organs (e.g., liver, kidneys, pancreas, and intestines) (Truog, 2007). The capacity for consciousness is the only feature that differentiates brain-dead patients from those who are alive. Nonetheless, brain-dead patients are in an irreversible coma with apnea and they are dependent on mechanical ventilation (Zamperetti et al., 2004). Patients who have irreversible cessation of higher brain function and brain-stem function or who are brain dead can survive on mechanical ventilation for several days to years (Maruya et al., 2008; Shewmon, 1998). Because these survivors have displayed coordinated physiological functions, including growth to puberty (President's Council on Bioethics, 2007b) and completion of pregnancy and delivery of a live infant (Truog, 2007), they cannot be considered really dead from a biological perspective. Therefore, brain-death criteria should not be equated with biological or somatic death in human beings (Capron, 2001).

Clinical and histopathologic observations indicate that there are serious flaws in the brain criteria used to make a declaration of death in a human being for HBOD (Table 3). First, the brain-death criteria that permit HBOD do not totally exclude residual brain function, including hormonal and neural responses to nociception and pain during procurement (Joffe, 2007b). Surgical procurement is performed on donors with no general anesthesia with hemodynamic responses suggestive of organisms in distress (Young \& Matta, 2000). Second, more than $60 \%$ of heart-beating organ donors who fulfill the clinical diagnosis for brain death have minimal or no structural disruption of the brain stem on autopsy (Wijdicks \& Pfeifer, 2008) to validate the notion of irreversible cessation of its function. The misclassification of patients as brain dead can lead to fatal consequences when patients whose condition may be salvageable (i.e., amenable to treatment) or reversible are determined instead to be brain dead (Morales, 2008).

The inconsistent times at which death is declared in NHBOD is equally controversial because 75 seconds to 5 minutes of circulatory arrest is too short a period to ensure uniformity in the determination of death in donors (Joffe, 2007a; Veatch, 2008). A declaration of death by circulatory criterion of loss of arterial pulse at E2a (Table 2) can be followed by spontaneous cardiac autoresuscitation (i.e., spontaneous recovery of cardiac and brain functions including those in the brain stem) at E3 (Table 2) after as long as 10 to 15 minutes of circulatory arrest in human beings (Joffe, 2007a; Rady, Verheijde \& McGregor, 2007). The President's Commission for the Study of Ethical Problems in Medicine and Biomedical and Behavioral Research 
(1981) has recommended that the criterion of circulatory arrest is longer than 15 minutes to ensure that there has been an irreversible cessation of function of the whole brain, including the brain stem, for a uniform determination of death. Circulatory arrest of 75 seconds to 5 minutes does not ensure the irreversible cessation of function of the whole brain or of circulation in NHBOD. Nevertheless, the transplant community has accepted this criterion for a declaration of death on the basis of two assumptions: 1) the "permanent" loss of vital signs of life is at 75 seconds of circulatory arrest (Bernat et al., 2006; Shemie, 2007) and 2) the moment of "permanent" loss of arterial pulse at E2a (Table 2) is equivalent to the moment of "irreversible" cessation of vital signs and whole-brain functions mandated by the UDDA at E7 (Table 2) (National Conference of Commissioners on Uniform State Laws, 1981; The President's Commission, 1981). These two assumptions disregard the biological events commonly observed during the dying process in human beings and fail to differentiate between the prognosis (i.e., incipiently dying or destined to die) and the diagnosis of death (i.e., really dead), which thus allows the early procurement of organs. Although a patient is incipiently dying at the moment of loss of arterial pulse at E2a (Table 2), that patient is not really dead until the moment of irreversibility of cessation of whole-brain functions at E7 (Table 2). The substitution of the permanence standard for the irreversibility standard to declare death for organ procurement violates the legal statute of death (McGregor, Verheijde \& Rady, 2008).

\section{Defending Organ Procurement from the Incipiently Dying Donor}

Despite the inherent uncertainty in either brain or circulatory criteria for a declaration of death, the utility of conflating the prognosis (i.e., incipiently dying or destined to die) with the diagnosis of death (i.e., really dead) has been morally defended for the purpose of organ donation and transplantation (Bernat, 2006; Shemie, 2007; Shewmon, 2004; Truog, 2007). Shewmon has argued that non-vital organs (e.g., liver, kidneys, pancreas, or intestines) can be removed in heart-beating donors at any moment between E0 (i.e., before loss of vital signs) and E2a (i.e., loss of arterial pulse) (Table 2) on the assumption that this action does not harm the donor and can only cause death from the systemic consequences of the lack of liver, kidneys, or intestinal functions that would develop over several days, which is beyond the timeline of the natural dying process (Shewmon, 2004). This argument is flawed because the surgical procedures required to procure these organs exert immediate and deleterious consequences on the cardiocirculatory system within seconds that directly hasten the dying process timeline from E0 to E7 
(Table 2). First, intravenous medications such as heparin and phentolamine mesylate are given to the organ donor for the purpose of organ preservation (D'Alessandro et al., 2000). Heparin is administered for systemic anticoagulation to facilitate subsequent organ flush-out, which can precipitate internal or external hemorrhage or both (Motta, 2005). Phentolamine is administered to prevent vasospasm, which can induce profound hypotension (Phua et al., 2007). These drugs can trigger hemorrhage or brain-stem herniation or both, as well as early cardiorespiratory arrest, and thus they can hasten the dying process in the donor. Second, the process of surgical organ procurement results in the instrumentation and interruption of the aorta and inferior vena cava, the major blood vessels connected to the heart (D'Alessandro et al., 2000). Vascular instrumentation enables rapid exsanguination of the circulating blood and replacement with cold preservative fluids within the native circulatory system for organ preservation (Casavilla et al., 1995). The direct disruption of the cardiocirculatory system to procure organs can accelerate the dying process within seconds, independent of the loss of the liver, kidneys, pancreas or intestines.

An alternative scenario has been suggested as a way to procure vital organs without necessarily being the cause of death (Shewman, 2004). Use of a cardiopulmonary bypass machine (i.e., an artificial heart-lung machine) might be initiated in a terminally ill patient at E0 (Table 2) to allow the removal of the native vital organs (e.g., heart and lungs) for transplantation before death while artificially maintaining systemic circulation and oxygenation in the donor; later discontinuation of the use of the cardiopulmonary bypass machine could then be done on the premise that its continued use is medically futile. Thus, it might be argued that the cause of death would be the discontinuation of the cardiopulmonary bypass machine (a nonbeneficial intervention) rather than the prior removal of vital organs. The above scenario is analogous to the initiation of mechanical ventilation (for artificial respiration) in a dying patient prior to the administration of neuromuscular-blocking medications that cause paralysis of the respiratory muscles and abolish spontaneous respiration. Mechanical ventilation could then be discontinued in the dying patient on the premise that the intervention is medically nonbeneficial at the end of life. From a legal perspective, it is not the discontinuation of mechanical ventilation but rather the administration of neuromuscular-blocking medications inducing respiratory muscle paralysis that is the proximate cause of death (Rohr, 2000).

Cardiopulmonary bypass machines may be used artificially to circulate oxygenated blood after spontaneous circulatory arrest in NHBOD (UNOS, 2007). However, artificial circulation can recommence the blood flow to the 
brain and the heart and can lead to the recovery of spontaneous functions during organ procurement (Dejohn \& Zwischenberger, 2006; Shemie, 2007). Medications are often required to suppress return of spontaneous brain and cardiac functions in donors with complete sparing of higher brain functions (e.g., with pulmonary disease, musculoskeletal disorders, or spinal cord disease) who are declared dead by the circulatory criterion. The administration of medications to suppress spontaneous cardiac and higherbrain or lower-brain stem functions can be considered a means to actively shorten or hasten the dying process.

Bernat has also provided reasons why NHBOD is permissible even if performed on the incipiently dying donor (2006):

First, as I have shown, if the patient is not dead at five minutes of asystole, the patient is incipiently and unequivocally dying, and will certainly be dead within minutes. Second, a state of irreversibility of cessation of breathing and circulation rapidly and inescapably follows the demonstration of permanent cessation of function. Third, the outcome difference between a permanency and an irreversibility standard is inconsequential. Fourth, the patient or surrogate has provided consent to permit organ removal at this stage, saying that a condition of permanence comprises sufficient grounds for determining death from the patient's perspectives. Fifth, other patients benefit from donation of the organs, so it constitutes a socially desirable goal. Sixth, the U.S. Department of Health and Human Services and expert advisory bodies (for example, the Institute of Medicine) favor and encourage this type of transplantation activity. And, finally, the dead donor rule was developed to prevent organ donors from being killed for their organs. But violating it in this case does not lead to the death of the patient,.... If critics wished to assign causation to the death of the patient, what "killed" the DCD [or NHBOD] patient was the earlier withdrawal of life-sustaining therapy, an act that is widely practiced and constitutionally protected, and, according to DCD protocols, would have been performed irrespective of organ donation.

The first three reasons collectively represent a perspective of moral nihilism. The realities of the last four reasons are questionable. In 2006, the Revised UAGA introduced a default rule of initiating measures (and use of life support systems) for preserving transplantable organs before death without prerequisite voluntary consent to donation (Verheijde, Rady \& McGregor, 2007a). Also, donating organs from the incipiently dying or the not really dead patients has never been publicly debated to proclaim that such an action is a socially desirable goal on behalf of the general public. It is also open to debate as to whether a governmental agency or private organization favoring a specific medical practice should necessarily make 
that judgment either morally acceptable or compliant with prevailing cultural and religious values in society. Bernat also conflates two distinctive actions by physicians at the end of life: withdrawal of life support systems (to discontinue a treatment) versus organ procurement (to administer an intervention). The intent and causation of medical actions determine their implications in end-of-life care (Rich, 2007). The first action is to discontinue a treatment (e.g., withdrawal of life support systems) to avoid further harm (i.e., pain and suffering) in a dying patient. Death ultimately ensues at an unpredictable time in a matter of minutes, hours, or days because of the underlying illness. The second action is to administer an intervention (e.g., surgical removal of organs as described above) that inflicts harm (i.e., pain and suffering) without benefit to the dying patient. In this case, death ensues immediately at the precise time that the intervention is performed.

Truog has made a similar argument in defense of organ procurement for transplantation before death, even suggesting that society should sanction this act at the end of life (2007). He states that organ procurement and the withdrawal of life support systems at the end of life are similar acts performed by physicians that will both cause death.

Most deaths in ICU [intensive care units] (as many as 90 percent in some centers), follow the withdrawal of mechanical ventilation. In these cases, in the act of removing the ventilator, the physician is the proximate cause of the patient's death. This act is not regarded as a homicide, however, because it is done in a particular context, by an individual (the physician) in a role sanctioned by society, and with the consent of the patient or surrogate. Procurement of organs by physicians can be ethically justified by parallel reasoning (2007).

However, Truog's parallel reasoning about the withdrawal of life support systems and organ procurement as both being an act of homicide by a physician at the end of life disregards the fundamental differences in the intentionality and temporal causality of death in the two situations. When life support systems are withdrawn, the intent is to discontinue nonbeneficial treatment and permit the underlying terminal illness to proceed along its temporal course. It is the temporal progression of the patient's underlying illness rather than the withdrawal of life support systems that ultimately results in death within minutes, hours, or days. Thus, the underlying illness is the proximate cause of the patient's death. In contrast, when organs are procured before death, the intent is to perform a nonbeneficial potentially harmful intervention (i.e., the surgical removal of organs) in a timely manner before allowing the natural progression of illness to death. The act of removing organs becomes the immediate proximate 
cause of death and can be considered homicide, even when there has been voluntary patient and surrogate consent.

\section{The Interface of End-of-life Organ Donation with Islamic Beliefs}

\section{Islamic Opinions on Organ Donation}

Islam has granted reward for saving a human's life. Therefore, any treatment or prevention that is considered vital for the maintenance of the normal health of mankind is not only accepted but also recommended in Islam. The Islamic Council (Senior Ulama Commission) of Saudi Arabia ruled that it is permitted in Islam to remove organs from dead people to save the lives of others as long as the organ removal is conducted without inflicting harm on the donor and for the benefit of the recipient (El-Shahat, 1999). Between 1959 and 1998, at least eighteen religious opinions and conference proceedings were issued to permit cadaveric organ donation for transplantation (El-Shahat, 1999). In 1986, Muslim scholars approved the Resolution of the Pan-Islamic Council Jurisprudence on Resuscitation Apparatus in Amman, Jordan (El-Shahat, 1999). Brain-death criteria were officially accepted in the legal definition of death:

A person is pronounced legally dead and consequently, all dispositions of the Islamic law in case of death apply if one of the two following conditions has been established: (1) there is total cessation of cardiac and respiratory functions, and doctors have ruled that such cessation is irreversible; (2) there is total cessation of all cerebral functions and experienced specialized doctors have ruled that such cessation is irreversible and the brain has started to disintegrate. In this case, it is permissible to take the person off the resuscitation apparatus, even if the function of some organs e.g., heart, are still artificially maintained.

In the United Kingdom, the Muslim Law (Shariah) Council also accepted the brain-stem criteria of death as constituting the end of life in order to donate organs (Choo, 1995). In the United States, the Medical Ethics Committee of the Islamic Medical Association of North America approved irreversible cessation of whole-brain function, including that of the brain stem, to permit the withdrawal of life support systems for cadaveric organ donation (IMANA Ethics Committee, 2005).

The current understanding of human biological processes in the dying phase (Tables 2 and 3) does not support that either brain or circulatory criteria to declare death will ensure that organ donors are really dead before organ procurement. The evolving scientific knowledge about serious flaws in the brain criteria used for declaring death in human beings has not been 
taken into account in Muslim countries when laws were drafted on the ethical and legal aspects of organ donation in brain-dead individuals (Akrami, et al., 2004; Meng, et al., 2004; Parry, 2008). It is unclear whether past Islamic rulings that permit organ procurement in brain-dead patients have been based on equating the criteria of death in human beings with either the loss of personhood or the loss of integration of biological functions as living organisms. If brain criteria are equated with death in human beings because of the loss of personhood (Hague, 2008), then organs can be procured in other irrecoverable neurological conditions with altered cognition and consciousness such as persistent vegetative states, dementia, severe mental retardations, and anencephaly. If brain criteria are equated with death in human beings because of the loss of integration of biological functions as living organisms, then Muslim scholars will need to reevaluate previous Islamic rulings. It is also unclear if past Islamic rulings permitting cadaveric organ donation from brain-dead individuals should be applicable to NHBOD in which life support systems and medications are administered to dying patients, perhaps with normal brain functions, before death for organ preservation (Zeiler et al., 2008). End-of-life practices in organ donation pose several key questions: Should conflating the prognosis (i.e., incipiently dying) with the diagnosis of death (i.e., really dead) be accepted for the purpose of procuring transplantable organs? Should procedures for organ preservation and procurement be permitted if they actively influence the timeline of the dying process? Should Islamic rulings consider not only the goal of saving the lives of organ recipients but also the effects of organ donation on the care of dying patients and their families? To answer these questions, we must first examine Islamic views on dying, death, and end-oflife care.

\section{Islamic Views on Dying and Death}

A few Muslim scholars have opposed cadaveric organ donation because they viewed that the brain criteria of death are not the traditional Islamic view of death (Al-Mousawi, Hamed \& Al-Matouk, 1997). These dissenting scholars understand the traditional view of death in human beings to be connected with the complete cessation of heartbeat, breathing, and whole-brain function, which results in a cold body and the onset of rigor mortis at the moment of E8 (Table 2) (Hedayat, 2006). In contrast, many Muslim scholars have ruled to permit cadaveric organ donation based on brain criteria of death. They based their opinions on the principle that all biological functions and somatic integration as living organisms have ceased irreversibly when death has been declared in human beings (El-Shahat, 1999; Hassaballah, 
1996; Shaheen \& Souqiyyeh, 2004). Nevertheless, the signs of life can be inferred from the Quran: "Then He fashioned him in due proportion, and breathed into him the Ruh [soul] (created by God for that person), and $\mathrm{He}$ gave you hearing (ears), sight (eyes) and heart. Little is the thanks you give!" (32:9, emphasis added). Muslim scholars have interpreted the words "the soul" and the "heart" in this verse in two different ways. Muslim scholars in favor of organ donation have interpreted both words as referring to human brain function (Choo, 1995). Dissenting Muslim scholars have interpreted the heart as a component of the soul separate from hearing and sight, which are related to brain function (Al-Mousawi, Hamed \& AlMatouk, 1997). In light of the scientific knowledge about the integrity of biological processes in brain-dead human beings, a more likely interpretation of this verse is that the beating heart is connected to the soul. This verse can be interpreted to mean that the soul continues to exist within the human body as long as either the brain or the heart is capable of functioning.

The question that remains to be answered is a theological one connected with the location of the human soul in relation to the body at the time of death. In Islam, life is a journey through the physical world, whereas death is a journey through the spiritual world (Hedayat, 2006). Death in Islam is an active process, a transition for the soul from the physical world to the spiritual world. The Prophet Muhammad explained, "Death is when the spirit [soul] leaves the body," which ends the relationship between the soul and the body (Hedayat, 2006). The Quran offers an explicit reminder that human beings have deficient understanding and knowledge about the soul or spirit (Ruh) and what constitutes life or death. "And they ask you concerning the Ruh (the Spirit); Say: "The Ruh (the Spirit): is one of the things, the knowledge of which is only with my Lord. And of knowledge, you (mankind) have been given only a little" (17:85) (Quran). This perspective on dying and death is distinctive in traditional Islamic teachings (Gatrad, 1994; Sarhill et al., 2001; Sheikh, 1998). For end-of-life rituals, a person is not considered to be dead until the body has become cold and rigor mortis has occurred. Thus, the immediate family and other relatives are allowed to stay with the patient to continue with end-of-life rituals until completion of the dying process and until the signs of death have become apparent to them. Once death is declared, a Muslim corpse is given the same respect and privacy as the person received while alive. Islamic belief holds that it may even be possible for the deceased to perceive pain. In the words of the Prophet Muhammad, "The breaking of a bone of a dead person is equal in sin to doing this while he was alive" (Gatrad, 1994). This strong belief in the sacredness of the body and its ownership by God means that God alone can decide its fate, and so the temporal user does not have a free hand to give 
away organs (Alkhawri, Stimson \& Warrens, 2005). "O you who believe! Betray not God and His Messenger, nor betray knowingly your amanat (things entrusted to you and all the duties which God has ordained for you)" (8:27) (Quran). Some Muslim scholars interpret that the human body is a trust or "amanat" given by God to man as meaning that there is no permissibility whatsoever for the transplantation or donation of organs (House of Lords European Union Committee, 2008). The Islamic belief that the body is resurrected after death, when God calls people to account on Judgment Day, strengthens the view that it is desirable for the body to remain whole for burial. Islamic traditions generally prohibit the manipulation or disfigurement of the body after death, e.g., for purposes of autopsy (Sarhill et al., 2001). Thus, the removal of organs may be viewed as a violation of this precept. Embalming and injecting preservative fluids into the body are also contrary to Islamic practice. Instead, the religious requirement is for the untampered-with body to be buried as soon as possible after death.

\section{Islam and Assisted Death in End-of-Life Organ Donation}

The Islamic faith values human life. It values any means to save a human life, but it condemns the termination of a human life without just cause: "And kill not anyone whom God has forbidden, except for a just cause (according to Islamic law). This He has commanded you that you may understand" (6:151) (Quran). In Islam, a patient's right to die voluntarily is not recognized because life is a divine trust and its term is fixed by an unalterable divine decree; therefore, it cannot be terminated by any form of active intervention (Gatrad, 1994; Sachedina, 2005). Muslim scholars who advocate organ donation commonly cite the verse: "if anyone killed a person - not in retaliation of murder, or (and) to spread mischief in the land - it would be as if he killed all mankind, and if anyone saved a life, it would be as if he saved the life of all mankind" (5:32) (Quran) emphasizing the latter, i.e., the saving of a human life being of a paramount value with such actions to be rewarded as if they involved the saving of the whole of mankind. What should be emphasized about this verse, however, is that its warning about, and condemnation of, the active termination of life or the killing of another human being has priority over the commendation for saving one.

When death becomes inevitable, Muslim patients should be allowed to die peacefully and comfortably without unnecessary procedures or new attempts to sustain life by artificial life support systems (Sarhill et al., 2001; Sheikh, 1998). However, life support systems are required to be initiated or continued to preserve organs for transplantation (Bernat et al., 2006; Snoeijs 
et al., 2007), contradicting Islamic principles about the care of the dying. Although it is recommended that nonbeneficial and painful interventions should be avoided at the end of life (Truog et al., 2008), procedures performed to preserve organs for donation are traumatic and may be painful for dying patients. Cardiopulmonary resuscitation can inflict physical injuries indistinguishable from those caused by violent assault (Hashimoto, Moriya \& Furumiya, 2007). The logistics of organ donation interrupt Islamic end-of-life rituals in several ways: 1) the dying patient is started or maintained on life support systems to preserve organs until surgical procurement can be accomplished (Verheijde, Rady \& McGregor, 2007a); 2) medical and surgical interventions to prepare for organ donation can disrupt the quality of palliative and end-of-life care delivered to the dying patient (Rady, Verheijde \& McGregor, 2007); 3) interventions required for organ preservation can influence the temporal course of the dying process (Motta, 2005; Phua et al., 2007); 4) resuscitative procedures (e.g., cardiopulmonary bypass) and the administration of medication to suppress spontaneous cardiac and brain reanimation may be applied after the declaration of death (Dejohn \& Zwischenberger, 2006); 5) the blood is drained from the body and replaced with preservative fluids before any organ is removed (D'Alessandro, 2000).

Any actions by physicians that are specifically intended to shorten the dying process or to hasten death and beyond what is required to relieve pain in dying patients are considered to be physician-assisted death or euthanasia (Sachedina, 2005). Organ donation can shorten the dying process in several ways because it may entail: 1) the excessive dosing with medications such as opioids and sedatives, normally used for palliation, to induce rapid terminal sedation; 2) the administration of medications and interventions to control the time of dying for organ preservation; 3 ) the expedition of the moment when surgical procurement can begin; and 4) the performance of interventions to suppress spontaneous reanimation during organ procurement. Any one of these acts can result in physician-assisted death. Truog (2008a) has explained that the brain criteria, which considers as "really dead" those patients who are actually in "irreversible coma", for the purpose of organ procurement is an example of physician-assisted death because it results in the active hastening of the dying process. Yet in Islam, physician-assisted death, with or without consent, is judged as an act of disobedience to God (Sachedina, 2005) and is strongly condemned: "And whoever kills a believer intentionally, his recompense is Hell to abide therein, and the Wrath and the Curse of God are upon him, and a great punishment is prepared for him" (4:93) (Quran).

To families of dying patients, the logistics of organ donation interrupt 
important rituals surrounding death in Islam (Hedayat, 2006; Sheikh, 1998). The expectations and spiritual experiences of families are strongly linked to the observance and respect of religious and cultural rituals at the end of life (Lobar, Youngblut \& Brooten, 2006). Traumatic memories in family members (Kesselring, Kainz \& Kiss, 2007) and moral distress in health care providers (Mandell et al., 2006) may ensue when end-of-life rituals are sacrificed for organ donation (Rady, Verheijde \& McGregor, 2007). The belief in human dignity may conflict with end-of-life practices in organ donation, which transforms a peaceful death into a "high-tech" death in an operating room environment surrounded by medical personnel ready to conduct the surgical removal of organs. Some families perceive surgical procedures performed on the recently deceased for the purpose of organ donation as a means of violating and desecrating the body while also prolonging the patient's suffering and destroying the deceased's actual physical appearance (Sque et al., 2008). These negative perceptions about end-of-life practices in organ donation can translate into complicated bereavement and unresolved grief reactions for the families of deceased donors. End-of-life practices for organ donation have been reported to complicate the bereavement process in more than $90 \%$ of such families (Soriano-Pacheco et al., 1999). As a result, families may experience a complicated bereavement of several months duration that includes severe depression, posttraumatic stress, poor physical health, and inability to cope with daily activities (Merchant et al., 2008). In Islamic cultures, the protection of the physical integrity and wholeness of the dead body is an important ritual for many families. Even after death, the body is to be treated with care, respect, and compassion for the sake of the person who occupied it in life. Not surprisingly, a survey of UK Muslims found that most respondents believed that organ donation had not been proven to help bereaved families cope with grief (Alkhawari, Stimson \& Warrens, 2005).

\section{Islam and the Consenting Process for Organ Donation}

Islam demands truthfulness and transparency in the disclosure of information about organ donation. This is the true foundation of voluntary informed consent. Concerns have been raised about the transparency of information disclosed to the general public to promote consent for organ donation (Long, Sque \& Addington-Hall, 2008). The inherent interests of the transplant community have introduced a self-serving bias in the selection of the quality and quantity of information about organ donation that is made available to the general public (Woien et al., 2006). Transplant advocates have insisted that information conveyed to families about end-of-life practices for organ 
donation should be limited only to information that would persuade and convince them to agree to donation (Howard, 2007). They have also encouraged organ requesters and procurement professionals to solicit the families of dying patients more explicitly (Table 4) for the donation of organs (Zink \& Wertlieb, 2006). Soliciting families for organ donation consent has raised serious doubts whether the consent process is truly voluntary and without coercion (Truog, 2008b). Consent for organ donation obtained through incomplete information disclosure violates fundamental Islamic principles about truthfulness and autonomy and brings into question the legitimacy of organ procurement. Most Muslim scholars agree that the decision to donate organs must be voluntary and without solicitation or coercion (Choo, 1995). Religious opinions favoring organ donation are often deployed for positive reinforcement of consent for organ donation (Woien, et al., 2006). The real and serious concerns about end-of-life practices in organ donation are often dismissed as myths. Effectively, consent for organ donation is encouraged by altering public perceptions and dismantling opposing traditional religious and cultural values (Alkhawari, Stimson \& Warrens, 2005; Cantarovich et al., 2007).

In Islam, it is fundamentally wrong to procure organs without prior permission of the deceased or a surrogate (Aksoy, 2001). Nevertheless, there has been global pressure to introduce presumed consent for organ donation (Hamm \& Tizzard, 2008; House of Lords European Union Committee, 2008; Howard, 2007). Within the presumed consent legislation, the default rule would be an implied agreement and consent to remove organs unless the individual has opted out by documented written refusal of donation. Presumed consent for organ donation has been advocated in the United Kingdom (Hamm \& Tizzard, 2008) and enacted in several European Union countries (e.g., Spain, Portugal, and Austria) (Mossialos, Costa-Font \& Rudisill, 2008). A UK survey of Muslims found strong objections to presumed consent for organ donation (Alkhawari, Stimson \& Warrens, 2005). A similar strong opposition to presumed consent for organ donation was also reported in a national U.S. survey (Gallup, 2005). Nonetheless, the U.S. Institute of Medicine and the transplant community have expressed interest for future U.S. legislation of presumed consent for organ donation (2006). Presumed consent for organ donation is interpreted as consent for performing all necessary interventions at the end of life for organ preservation including administration of medications and life support systems when patients are in the process of dying and before declaring death (Zeiler et al., 2008).

In the United States, the Revised UAGA in 2006 came about due to the efforts of the transplant organizations and the U.S. Institute of Medicine 
(National Conference of Commissioners on Uniform State Laws, 2006). The Revised UAGA maximizes the opportunities to procure organs from dying patients without explicitly legislating presumed consent. The Revised UAGA creates the default rule of presumption of intent (but not consent) to donate organs for transplantation by overriding advance directives that mandate the withholding or withdrawal of life support systems at the end of life (Verheijde, Rady \& McGregor, 2007a). The Revised UAGA permits the use of life support systems without prior explicit consent to preserve organs until the procurement professionals can determine the medical suitability of dying patients as potential organ donors and approach the patient's family about consent for donation (National Conference of Commissioners on Uniform State Laws, 2006). The exceptions to the default rule are individuals who have documented written refusal of donation (i.e., by opting out). In the United Kingdom, the Human Tissue Act of 2004 has also been translated into legitimizing non-consensual organ preservation interventions to increase the supply of transplantable organs in "uncontrolled" NHBOD (Bell, 2006). In other European countries with enforced presumed consent for donation, performing organ preservation interventions during the process of dying and before death without consent are interpreted to fall within the realm of this legislation (Zeiler et al., 2008).

Presumed consent refers theoretically to laws that permit the procurement or removal of organs without permission. However, performing interval measures for organ preservation, legally without consent can be viewed as instating a presumed consent system. It can be argued that both the Revised UAGA and the Human Tissue Act 2004 already have this system in place because the initial measures for organ preservation can occur without the patient or family consent (Bell, 2006; Verheijde, Rady \& McGregor, 2007a). In medical practice, procedures may be performed on a patient without express consent only in special circumstances that serve the best interests of that patient. When life support systems are administered for organ preservation without consent, the interests are not those of the patient but rather those of a third party (i.e., procurement professionals and potential organ recipients) (Verheijde, Rady \& McGregor, 2007b). For that reason, it has been argued that first-person consent is necessary to perform organ preservation procedures and interventions before death (Downie, Rajotte \& Shea, 2008). In multicultural societies, reliance on presumed (i.e., no) consent to the use of life support systems for organ preservation creates an unrealistic "one size fits all" approach toward end-of-life care. For certain cultural and religious groups, this approach may be potentially demeaning to the deceased and to subsequent generations of that family because of the symbolism, beliefs, and emotions associated with removing organs or 
causing bodily mutilation (Sarhill et al., 2001; Sque et al., 2008).

\section{Implications of End-of-life Organ Donation for the Muslim Communities}

We have outlined many practical aspects of end-of-life organ donation (such as antemortem resuscitation and procedures for organ preservation, redefining death, organ procurement from the incipiently dying, and lack of transparency in the consenting process) that conflict with Islam's core principles of care for the dying and their families. However, transplant advocates have exerted great efforts in promoting end-of-life organ donation for transplantation in Muslim communities worldwide without appropriate scholarly debate about its broad sociocultural ramifications. In the zeal to promote end-of-life organ donation through implementation and enforcement of legislation, an ideology is borne and disseminated worldwide dismantling traditional religious practices and sociocultural beliefs (Verheijde et al., 2008). It is imperative for the transplantation medical field not exclusively to rely on its technical capabilities and expertise in defining its societal role. The definition of its societal role should also take into account moral concerns, which are informed by best scientific evidence as well as by religious, cultural, and societal values. Religious, cultural, and societal values of the Islamic faith originate from the Quran and the Sunnah and should be the points of reference and guidance for Muslim scholars when reaching an opinion on what is permissible in end-of-life practices for organ donation. Not all persons (organ donors, recipients or transplant professionals) will comply with an Islamic opinion about end-of-life practices for organ donation; however, the moral status of actions transgressing against such a declared opinion must be established for those who wish to adhere to their faith. Consequently, living organ donation may increase to compensate for the loss of transplantable organs from dying patients shifting the harm to increasing numbers of living donors, which raises additional ethical questions.

\section{Conclusions}

Current understanding of human biological processes in the dying phase refutes the stance that either brain criteria or circulatory criteria of death ensure that donors are really dead before organ procurement. Life support systems are required to keep organs viable until they are procured for transplantation. Legislations have been introduced in several countries to permit the administration of life support systems for organ preservation 
without prior consent for organ donation. We conclude that: 1) many practical aspects of end-of-life organ donation conflict with the Islamic faith's core principles of care for the dying and their families; 2) defining the societal role of transplantation medicine is not uniquely a matter of accounting for technical capabilities and expertise, but must include the recognition of cultural, social, and religious values that constitute morality and guide best scientific evidence; 3) Muslim scholars should critically evaluate new evidence about end-of-life practices in organ donation, their effects on the care of terminally ill patients and their families and the consequences on the cultures of Muslim communities worldwide.

\section{REFERENCES}

Akrami, S. M., Osati, Z., Zahedi, F., et al. (2004). Brain death: recent ethical and religious considerations in Iran. Transplantation Proceedings, 36 (10), 2883-7.

Aksoy, S. (2001). A critical approach to the current understanding of Islamic scholars on using cadaver organs without prior permission. Bioethics, 15 (5/6): 461-472.

Al-Allaf, M. (2003). Part two: Islamic divine law (Shari'ah). 9. Structuring the life of man by divine law. The five Ahkam. Mirror of realization: God is a percept, the universe is a concept (pp. 48-56). Islamic Information Center, USA. [On-line] Available: http://books.google.com/ books?id = aR17gcq26ogC.

Al-Khader, A. A., Shaheen, F. A. \& Al-Jondeby, M. S. (2003). Important social factors that affect organ transplantation in Islamic countries. Experimental and Clinical Transplantation, 1 (2), 96-101.

AlKhawari, F. S., Stimson, G. V., Warrens, A. N. (2005). Attitudes toward transplantation in U.K. Muslim Indo-Asians in west London. American Journal of Transplantation, 5 (6), 1326-1331.

Al-Mousawi, M., Hamed, T., Al-Matouk H. (1997). Views of Muslim scholars on organ donation and brain death. Transplantation Proceedings, 29 (8), 3217.

Barnard, C. (1967). The operation. A human cardiac transplant: an interim report of a successful operation performed at Groote Schuur Hospital, Cape Town. South African Medical Journal, 41 (48), 1271-4.

Beecher, H., (1968). A definition of irreversible coma. Special communication: report of the Ad Hoc Committee of the Harvard Medical School to Examine the Definition of Brain Death. The Journal of the American Medical Association, 205, 337-340.

Beliefnet.com. An Islam Primer (2008). [On-line] Available: 
http://www.beliefnet.com/Faiths/Islam/2001/09/An-Islam-Primer.aspx (Accessed: August 16, 2008).

Bell, M. D. D. (2006). The UK Human Tissue Act and consent: surrendering a fundamental principle to transplantation needs? Journal of Medical Ethics, 32 (5), 283-286.

Bernat, J. (2006). Are organ donors after cardiac death really dead? Journal of Clinical Ethics, 17 (2), 122-132.

Bernat, J., D'Alessandro, A., Port, F., et al. (2006). Report of a national conference on donation after cardiac death. American Journal of Transplantation, 6 (2), 281-291.

Boucek, M., Mashburn, C., Dunn, S., et al. (2008). Pediatric heart transplantation after declaration of cardiocirculatory death. The New England Journal of Medicine, 359, 709-714.

Cantarovich, F., Heguilen, R., Filho, M. A., et al. (2007). An international opinion poll of well-educated people regarding awareness and feelings about organ donation for transplantation. Transplant International, 20 (6), 512-518.

Capron, A. M. (2001). Brain death - well settled yet still unresolved. The New England Journal of Medicine, 344 (16), 1244-6.

Casavilla, A., Ramirez, C., Shapiro, R., et al. (1995). Experience with liver and kidney allografts from non-heart-beating donors. Transplantation, 59 (2), 197-203.

Choo, V. (1995). UK Shariah Council approves organ transplants. The Lancet, 346 (8970), 303.

D’Alessandro, A. M., Hoffmann, R. M., Knechtle, S. J., et al. (2000). Liver transplantation from controlled non-heart-beating donors. Surgery, 128 (4), 579-588.

Dejohn, C. \& Zwischenberger, J. B. (2006). Ethical implications of extracorporeal interval support for organ retrieval (EISOR). ASAIO (American Society for Artificial Internal Organs) Journal, 52 (2), 119122.

Detry, O., Laureys, S., Faymonville, M., et al. (2008). Organ donation after physician-assisted death. Transplant International, 21 (9), 915.

DeVita, M. A., Snyder, J. V. (1993). Development of the University of Pittsburgh Medical Center policy for the care of terminally ill patients who may become organ donors after death following the removal of life support. Kennedy Institute of Ethics Journal, 3(2), 131-143.

Downie, J., Rajotte, C., Shea, A. (2008). Pre-mortem transplantation optimizing interventions: the legal status of consent. Canadian Journal of Anesthesia, 55 (7), 458-469.

El-Shahat, Y. I. M. (1999). Islamic viewpoint of organ transplantation. 
Transplantation Proceedings, 31 (8), 3271-4.

Gallup Organization Prepared for Division of Transplantation Health Resources and Services Administration (2005). The 2005 national survey of organ and tissue donation attitudes and behaviors. Attitudes toward presumed consent. [On-line] Available: http://www.organdonor.gov/ survey 2005/ presumed_consent.htm.

Gatrad, A. R. (1994). Muslim customs surrounding death, bereavement, postmortem examinations, and organ transplants. British Medical Journal, 309 (6953), 521-523.

Gatrad, A. R. \& Sheikh, A. (2001) Medical ethics and Islam: principles and practice. Archives of Disease in Childhood, 84 (1), 72-75.

Hamm, D. \& Tizzard, J. (2008). Presumed consent for organ donation. British Medical Journal, 336 (7638), 230.

Haque, O. S. (2008). Brain death and its entanglements. A redefinition of personhood for Islamic ethics. Journal of Religious Ethics, 36 (1), 13-36.

Hashimoto, Y., Moriya, F., Furumiya, J. (2007). Forensic aspects of complications resulting from cardiopulmonary resuscitation. Legal Medicine, 9 (2), 94-99.

Hassaballah, A. M. (1996). Definition of death, organ donation and interruption of treatment in Islam. Nephrology Dialysis Transplantation, 11 (6): 964-965.

Hedayat, K. (2006). When the spirit leaves: childhood death, grieving, and bereavement in Islam. Journal of Palliative Medicine, 9 (6), 1282-1291.

House of Lords European Union Committee (2008). 17th Report of Session 2007-08. Increasing the supply of donor organs within the European Union Volume I: Report. (HL Paper 123-I). Published 2 July. The Stationery Office, House of Lords European Union Committee. [On-line.] Available: http://www.publications.parliament.uk/ pa/ ld200708/ ldselect/ ldeucom/ 123/123i.pdf.

Howard, R. J. (2007). Missed opportunities: the Institute of Medicine Report: organ donation: opportunities for action. American Journal of Transplantation, 7 (1), 14-16.

IMANA Ethics Committee (2005). Islamic medical ethics: the IMANA perspective. JK-Practitioner: International Journal of Current Medical Science \& Practice, 12 (4): 231-237.

Institute of Medicine (1998). Non-heart-beating organ transplantation medical and ethical issues in procurement. Potts J. T. \& Herdman, R. (eds.) Washington, D.C.: National Academy Press.

Institute of Medicine, Committee on non-heart-beating transplantation - the scientific and ethical basis for practice and protocols division of health care services institute of medicine (2000). Non-heart-beating organ 
transplantation: practice and protocols. Washington, D.C.: National Academy Press.

Institute of Medicine, Committee on increasing rates of organ donationboard on health sciences policy (2006). Organ donation: opportunities for action. Childress J. F. and Liverman, C.T. (eds.) Washington, D.C: The National Academies Press.

Joffe, A. R. (2007a). The ethics of donation and transplantation: are definitions of death being distorted for organ transplantation? Philosophy, Ethics, and Humanities in Medicine, 2 (1). [On-line.] Available: http://www.peh-med.com/content/2/1/28.

Joffe, A. R. (2007b). The neurological determination of death: what does it really mean? Issues in Law and Medicine, 23 (2), 119-140.

Karakatsanis, K. G. (2008). Brain death: should it be reconsidered? Spinal Cord, 46 (6), 396-401.

Kauffman, H. M., Rosendale, J. D., Taranto, S. E., et al. (2007). Non-heartbeating donors (then) and donation after cardiac death (now). Transplantation Reviews, 21(4), 237-248.

Kesselring, A., Kainz, M. \& Kiss, A. (2007). Traumatic memories of relatives regarding brain death, request for organ donation and interactions with professionals in the ICU. American Journal of Transplantation, 7 (1), 211-217.

Laureys, S. (2005). Death, unconsciousness and the brain. Nature Reviews Neuroscience, 6 (11), 899-909.

Lobar, S. L., Youngblut, J. M., Brooten, D. (2006). Cross-cultural beliefs, ceremonies, and rituals surrounding death of a loved one (cultural practices). Pediatric Nursing, 32 (1), 44-50.

Long, T., Sque, M., Addington-Hall, J. (2008). What does a diagnosis of brain death mean to family members approached about organ donation? A review of the literature. Progress in Transplantation, 18 (2), 118-125.

Mandell, M. S., Zamudio, S., Seem, D., et al. (2006). National evaluation of healthcare provider attitudes toward organ donation after cardiac death. Critical Care Medicine, 34 (12), 2952-2958.

Maruya, J., Nishimaki, K., Nakahata, J., et al. (2008). Prolonged somatic survival of clinically brain-dead adult patient-case report. Neurologia medico-chirurgica, 48 (3), 114-117.

McGregor, J. L., Verheijde, J. L. \& Rady, M.Y. (2008). Do donation after cardiac death protocols violate criminal homicide statutes? Medicine and Law, 27 (2), 241-257.

Meng, C. J., Chong, T. S., Kassim, P. N. J., et al. (2004). The ethics and law on organ transplantation in Malaysia. NCD Malaysia, 3 (1), 2-5. [Online] Available: http://www.dph.gov.my/ncd/Bulletin/Jan_Mac04/03. 
The\%20 Ethnics.pdf.

Merchant, S. J., Yoshida, E. M., Lee, T. K., et al. (2008). Exploring the psychological effects of deceased organ donation on the families of the organ donors. Clinical Transplantation, 22 (3), 341-347.

Morales N. (2008). "Dead" man recovering after ATV accident. Doctors said he was dead, and a transplant team was ready to take his organs - until a young man came back to life. Dateline NBC News. [On-line.] Available: http://www.msnbc.msn.com/id/23768436/.

Mossialos, E., Costa-Font, J., Rudisill, C. (2008). Does organ donation legislation affect individuals' willingness to donate their own or their relative's organs? Evidence from European Union survey data. BMC health services research, 8,48 . [On-line] Available:

http://www.biomedcentral .com/1472-6963/8/48.

Motta, E. D. (2005). The ethics of heparin administration to the potential non-heart-beating organ donor. Journal of Professional Nursing, 21 (2), 97-102.

National Conference of Commissioners on Uniform State Laws (1981). The Uniform Determination of Death Act 1981. [On-line] Available: http://www.law.upenn.edu/bll/archives/ulc/fnact99/1980s/udda80.htm. (Accessed August 16, 2008).

National Conference of Commissioners on Uniform State Laws. Revised Uniform Anatomical Gift Act (2006) and Amendment (2007). [On-line] Available:http://www.anatomicalgiftact.org/DesktopDefault.aspx?tabinde $\mathrm{x}=0$ \&tabid $=1$. (Accessed August 16, 2008).

New England Journal of Medicine (2008). Perspective roundtable: organ donation after cardiac death. [On-line] Available: http://content.nejm.org/cgi/content/full/359/7/669/DC1.

Padela, A. I. (2007). Islamic medical ethics: a primer. Bioethics, 21 (3), 16978.

Parry, J. (2008). Doctors hope consensus on brain death in China will boost transplants. British Medical Journal, 336 (7644), 581.

Phua, J., Lim, T., Zygun, D., et al. (2007). Pro/con debate: in patients who are potential candidates for organ donation after cardiac death, starting medications and/or interventions for the sole purpose of making the organs more viable is an acceptable practice. Critical Care, 11 (2), 211. [On-line] Available: http://ccforum.com/content/11/2/211.

President's Commission for the Study of Ethical Problems in Medicine and Biomedical and Behavioral Research. (1981). Defining death: a report on the medical, legal and ethical issues in the determination of death. Washington, D.C.: Government Printing Office. [On-line] Available: http://www.bioethics.gov/reports/past_commissions/index.html. 
(Accessed August 16, 2008).

President's Council on Bioethics (2007a). Session 1: The draft white paper on the determination of death. Discussion by council members. [On-line] Available: http://www.bioethics.gov/transcripts/sept07/session1.html. (Accessed August 16, 2008).

President's Council on Bioethics (2007b). Session 5: Response to the council's white paper, "Controversies in the determination of death" (D. Alan Shewmon). [On-line] Available from: www.bioethics.gov/ transcripts/nov07/session5.html. (Accessed August 16, 2008).

Rady, M.Y., Verheijde, J. L., McGregor, J. (2007). Non-heart beating or cardiac death organ donation: why we should care. Journal of Hospital Medicine, 2 (5), 324-334.

Rich, B. A. (2007). Causation and intent: persistent conundrums in end-oflife care. Cambridge Quarterly of Healthcare Ethics, 16 (1), 63-73.

Rifkinson-Mann, S. (2003). Legal consequences and ethical dilemmas of pain perception in persistent vegetative states. Journal of Health Law, 36 (4), 523-548.

Rohr, W. B. (2000). Neuromuscular blockade at the end of life. The New England Journal of Medicine, 342 (25), 1921-2.

Sachedina, A. (2005). End-of-life: the Islamic view. The Lancet, 366 (9487), 774-779.

Sarhill, N., LeGrand, S., Islambouli, R., et al. (2001). The terminally ill Muslim: death and dying from the Muslim perspective. The American Journal of Hospice \& Palliative Care, 18 (4), 251-255.

Shaheen, F. A. M. \& Souqiyyeh, M. Z. (2004). Increasing organ donation rates from Muslim donors: lessons from a successful model. Transplantation Proceedings, 36 (7), 1878-80.

Sheikh, A. (1998). Death and dying - a Muslim perspective. Journal of the Royal Society of Medicine, 91 (3), 138-140.

Shemie, S. D. (2007). Clarifying the paradigm for the ethics of donation and transplantation: was 'dead' really so clear before organ donation? Philosophy, Ethics, and Humanities in Medicine, 2 (1), 18. [On-line] Available: www.peh-med.com/content/2/1/18.

Shewmon, D. A. (1998). Chronic "brain death": meta-analysis and conceptual consequences. Neurology, 51 (6), 1538-45.

Shewmon, D. A. (2004). The dead donor rule: lessons from linguistics. Kennedy Institute of Ethics Journal, 14, 277-300.

Snoeijs, M. G. J., van Heurn, L.W.E., van Mook, W.N.K.A., et al. (2007). Controlled donation after cardiac death: a European perspective. Transplantation Reviews, 21 (4), 219-229.

Soriano-Pacheco, J. A., Lopez-Navidad, A., Caballero, F., et al. (1999). 
Psychopathology of bereavement in the families of cadaveric organ donors. Transplantation Proceedings, 31 (6), 2604-5.

Sque, M., Long, T., Payne, S., et al. (2008). Why relatives do not donate organs for transplants: 'sacrifice' or 'gift of life'? Journal of Advanced Nursing, 61 (2), 134-144.

Starzl, T., Groth, C., Brettschneider, L., et al. (1968). Orthotopic homotransplantation of the human liver. Annals of Surgery, 168 (3), 392415.

The Quran. Mohsin Khan-English Translation. [On-line] Available: http://www.quranexplorer.com/Quran/ (Accessed August 16, 2008).

Truog, R. D. (2007). Brain death - too flawed to endure, too ingrained to abandon. Journal of Law Medicine \& Ethics, 35 (2), 273-281.

Truog, R. D. (2008a). End-of-life decision-making in the United States. European Journal of Anaesthesiology Supplement, 25 (Supplement S42), 43-50.

Truog, R. D. (2008b). Consent for organ donation - balancing conflicting ethical obligations. The New England Journal of Medicine, 358 (12), 1209-1121.

Truog, R. D., Campbell, M. L., Curtis, J. R., et al. (2008). Recommendations for end-of-life care in the intensive care unit: a consensus statement by the American College of Critical Care Medicine. Critical Care Medicine, $36(3), 953-963$.

Truog, R. D., Miller, F. G. (2008). The dead donor rule and organ transplantation. The New England Journal of Medicine, 359 (7), 674-675.

United Network For Organ Sharing (2007). Bylaw 145. Bylaws Appendix B Attachment III DCD Recovery Protocol Model Elements [On-line] Available: www.unos.org/ policiesandBylaws2/ bylaws/UNOSByLaws/ DOCs/bylaw_145.doc. (Accessed August 16, 2008).

Veatch, R. M. (2008). Donating hearts after cardiac death - reversing the irreversible. The New England Journal of Medicine, 359 (7), 672-673.

Verheijde, J. L., Rady, M. Y., McGregor, J. L. (2007a). The United States Revised Uniform Anatomical Gift Act of 2006: new challenges to balancing patient rights and physician responsibilities. Philosophy, Ethics, and Humanities in Medicine, 2 (1), 19. [On-line] Available: www.peh-med.com/content/2/1/19.

Verheijde, J. L., Rady, M. Y., McGregor, J. L. (2007b). Defining the scope of implied consent in the emergency department: shortchanging patients' right to self determination. American Journal of Bioethics, 7 (12), 51-52.

Verheijde, J. L., Rady, M. Y., McGregor, J. L., et al. (2009). Enforcement of presumed-consent policy and willingness to donate organs as identified in the European Union Survey: the role of legislation in reinforcing 
ideology in pluralistic societies. Health Policy, 90 (1), 26-31.

Wijdicks, E. \& Pfeifer, E. (2008). Neuropathology of brain death in the modern transplant era. Neurology, 70 (15), 1234-7.

Woien, S., Rady, M. Y., Verheijde, J. L., et al. (2006). Organ procurement organizations internet enrollment for organ donation: abandoning informed consent. BMC Medical Ethics, 7 (12), [On-line] Available: http://www.biomedcentral.com/1472-6939/7/14.

Young, P.J., Matta, B.F. (2000). Anaesthesia for organ donation in the brainstem dead - why bother? Anaesthesia, 55 (2), 105-106.

Zamperetti, N., Bellomo, R., Defanti, C. A., et al. (2004). Irreversible apnoeic coma 35 years later. Intensive Care Medicine, 30 (9), 1715-22.

Zeiler, K., Furberg, E., Tufveson, G., et al. (2008). The ethics of non-heartbeating donation: how new technology can change the ethical landscape. Journal of Medical Ethics, 34 (7), 526-529.

Zink, S., Wertlieb, S. (2006). A study of the presumptive approach to consent for organ donation: a new solution to an old problem. Critical Care Nurse, 26 (2), 129-136.

Figure 1. The criteria applied to organ donation at the end of life have been abbreviated to expand the pool of eligible organ donors for transplantation over the past 4 decades.

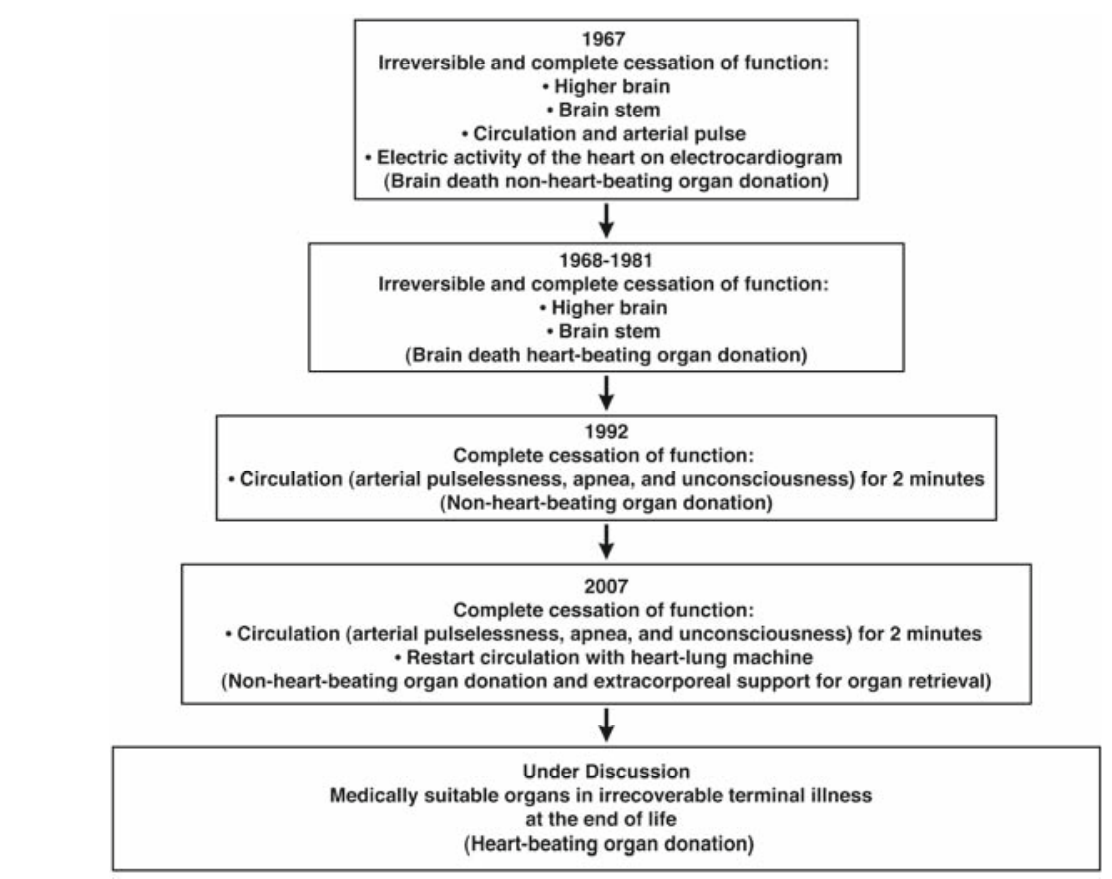

Legend

1967 Starzl and Bernard performed landmark successful cases of liver and heart transplants, respectively 
(Barnard, 1967; Starzl et al., 1968).

1968 The Ad Hoc Committee of the Harvard Medical School developed the brain criteria of death (Beecher, 1968), and the Uniform Anatomical Gift Act was enacted

1981 The President's Commission (1981) published the report on defining death and the medical, legal and ethical issues in the determination of death; and the Uniform Determination of Death Act was enacted

1992 The University of Pittsburgh Medical Center developed the non-heart-beating organ donation protocol (DeVita \& Snyder, 1993).

2007 The United Network for Organ Sharing established guidelines for non-heart-beating organ donation and extracorporeal support for organ retrieval (UNOS, 2007).

Under discussion. The President's Council on Bioethics (2007) and New England Journal of Medicine Roundtable (2008) discuss heart-beating organ donation in irrecoverable terminal illness at the end of life (2008).

Figure 2. Non-heart-beating organ donation-related procedures.

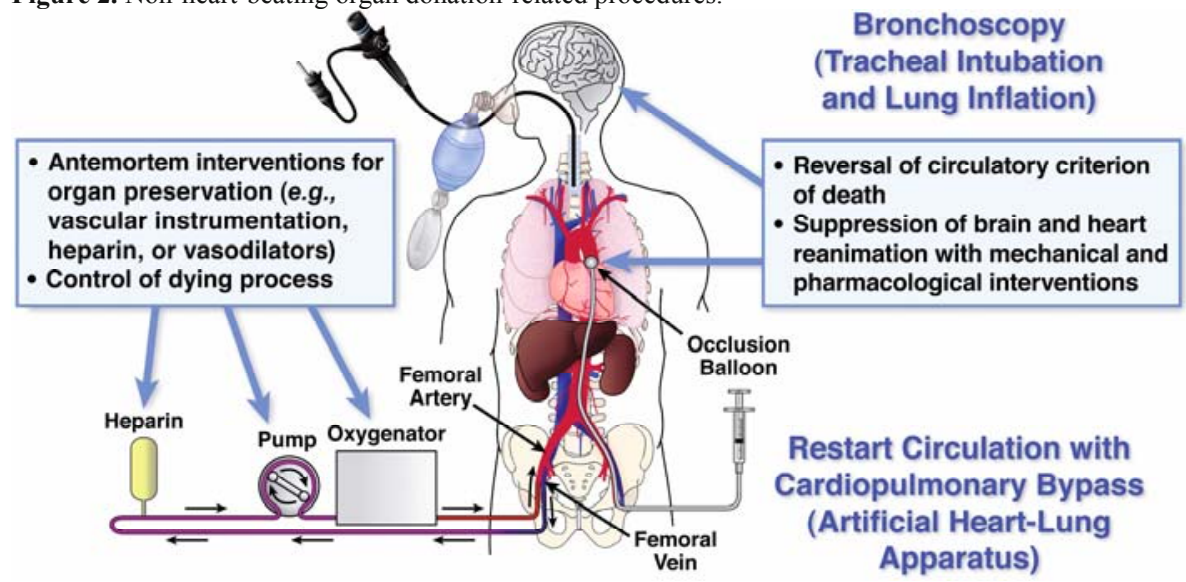

Legend. Antemortem interventions performed for organ preservation can control the timeline of the dying process. The use of a cardiopulmonary bypass machine (artificial heart-lung apparatus) is initiated for the artificial circulation of oxygenated blood necessary for organ preservation, which reverses the circulatory criterion of death (Dejohn and Zwischenberger, 2006; UNOS, 2007). Tracheal intubation and lung insufflations are required for bronchoscopy (UNOS, 2007).

Table 1. Some of the General Principles of Islam for Rendering Opinions on the Moral Status of Actions and the Five Ruling Values of Actions With Their Consequences in the Here and Now and in the Hereafter. (Adapted from sources Al-Allaf, 2003; Padela, 2007).

\begin{tabular}{|cl|}
\hline Rules for Opinions on Moral Status of Actions \\
\hline$\bullet$ & God alone defines the standard of right and wrong \\
- & Good deeds are good only because God commands them, and evil is evil because God \\
forbids it \\
- God's commands are purposeful and, as such, His Will extends to all areas of life and \\
every field of action \\
- Need and necessity are equivalent \\
- $\quad$ Injurious harm should be removed \\
- $\quad$ Prevention of evil has priority over obtaining benefit \\
The greater benefit prevails over the lesser benefit
\end{tabular}




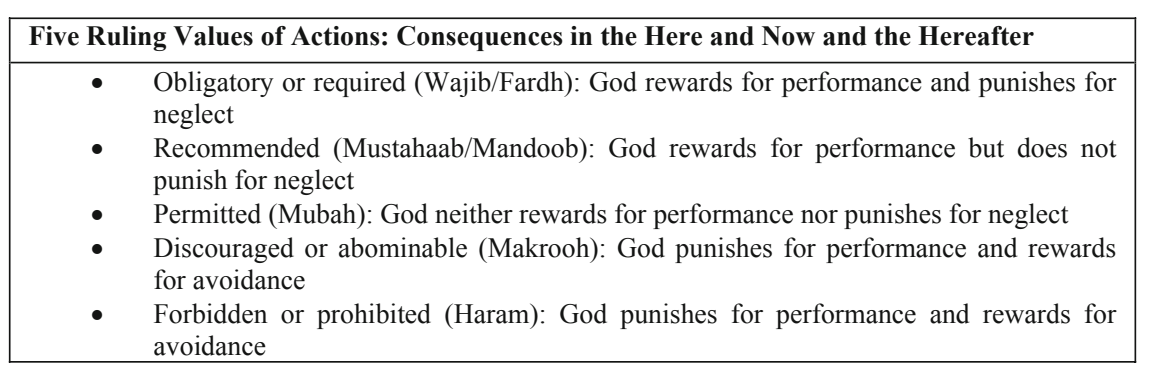

Table 2. A Description of the Timeline of Human Biological Processes and the Events of the Dying Process and Their Relationship to Non-Heart-Beating Organ Donation for Transplantation Practice. E = event. (Adapted from source: Shewmon, 2004).

\begin{tabular}{|c|c|c|}
\hline Event & Description & Organ Donation Practice \\
\hline E0 & $\begin{array}{l}\text { Terminally ill patient } \\
\text { (heart beating; spontaneous respiration) }\end{array}$ & $\begin{array}{l}\text { Irrevocable brain injury } \\
\text { Irrevocable spinal cord disease } \\
\text { End-stage pulmonary disease } \\
\text { End-stage musculoskeletal disease } \\
\text { Terminal diagnosis and prognosis }\end{array}$ \\
\hline E1 & Apnea (loss of spontaneous respiration) & \\
\hline E2a & Loss of arterial pulse & $\begin{array}{l}\text { Circulatory arrest for } 75 \text { seconds to } 5 \\
\text { minutes (permanence standard) } \\
\text { Non-heart-beating organ donation }\end{array}$ \\
\hline $\mathrm{E} 2 \mathrm{~b}$ & $\begin{array}{l}\text { Electrical cardiac asystole on electrocardiogram } \\
\text { (loss of electrical activity) }\end{array}$ & \\
\hline E3 & Loss of potential for cardiac autoresuscitation & \\
\hline E4 & Loss of potential for interventional resuscitation & \\
\hline E5 & Onset of permanent loss of consciousness & \\
\hline E6 & Loss of potential for recovery of consciousness & \\
\hline E7 & $\begin{array}{l}\text { Irreversible cessation of whole-brain function, } \\
\text { including brain-stem function }\end{array}$ & $\begin{array}{l}\text { Legal statute of the Uniform } \\
\text { Determination of Death Act (1981) } \\
\text { (irreversibility standard) } \\
\text { Brain death; non-heart-beating organ } \\
\text { donation }\end{array}$ \\
\hline E8 & Cold skin discoloration and limb rigor mortis & Traditional Islamic view of death \\
\hline
\end{tabular}

Table 3. Clinical Criteria for Brain Death and Contemporary Medical Arguments For and Against Equating Brain Death with Death in Human beings. (Adapted from multiple sources: Karakatsanis, 2008; Wijdicks and Pfeifer, 2008).

\begin{tabular}{|c|c|}
\hline Clinical criteria of whole-brain death \\
\hline Irreversible loss of \\
- $\quad$ Wakefulness and awareness (i.e., coma) \\
- $\quad$ Motor responses to pain in all extremities \\
- $\quad$ Brain stem reflexes \\
\hline
\end{tabular}




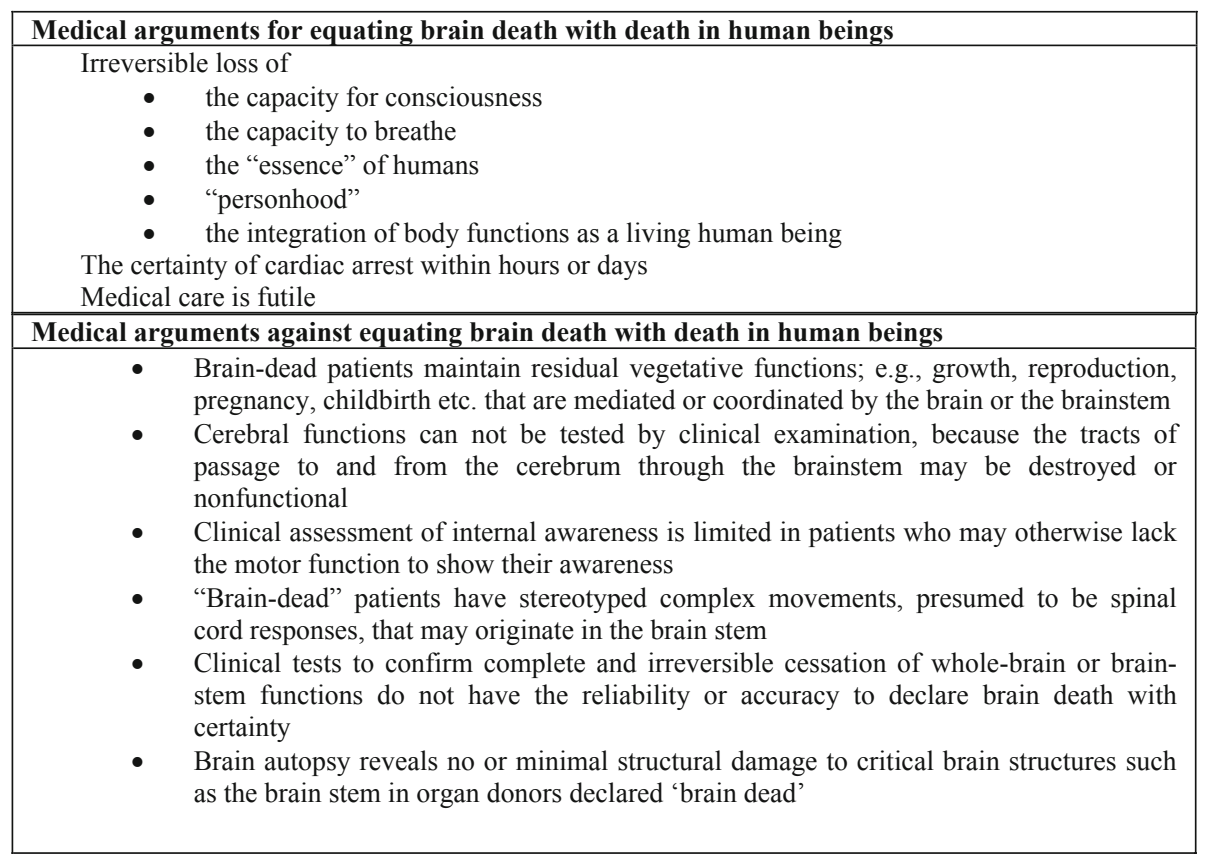

Table 4. How Organ Procurement Organizations and Organ Requesters Approach Family Members for Voluntary Consent and Solicitation Consent for Organ Donation in the United States. (Adapted from source: Zink and Wertlieb, 2006).

\begin{tabular}{|l|l|}
\hline Approach for Voluntary Consent & Approach for Solicited Consent \\
\hline $\begin{array}{l}\text { The intention of the request is a voluntary } \\
\text { consent (e.g., if you decide to donate) }\end{array}$ & $\begin{array}{l}\text { The intention of the request is a presumptive consent } \\
\text { (e.g., when you decide to donate) }\end{array}$ \\
\hline Requesters act as grief counselors & $\begin{array}{l}\text { Requesters are introduced to the family of a potential } \\
\text { donor as part of the medical team or as a donation } \\
\text { expert }\end{array}$ \\
\hline No correlative action & $\begin{array}{l}\text { Requesters use a presumptive transition between the } \\
\text { discussion about brain death and a conversation about } \\
\text { donation }\end{array}$ \\
\hline $\begin{array}{l}\text { Requesters are viewed as advocates of the } \\
\text { families of potential donors }\end{array}$ & $\begin{array}{l}\text { Requesters are viewed as advocates for transplant } \\
\text { recipients }\end{array}$ \\
\hline $\begin{array}{l}\text { No correlative action } \\
\text { Requesters use explicit references to transplant } \\
\text { recipients during the conversation (e.g., gift of life, } \\
\text { saving of life, organ sharing, or organ gift) }\end{array}$ \\
\hline $\begin{array}{l}\text { Requesters use value-neutral language } \\
\text { (e.g., We are here to provide you with } \\
\text { information about organ donation) }\end{array}$ & $\begin{array}{l}\text { Requester use value-positive language (e.g., we are here } \\
\text { to provide you with the opportunity to donate your } \\
\text { loved one's organs) }\end{array}$ \\
\hline $\begin{array}{l}\text { Requesters' approach is neutral (e.g., Did } \\
\text { you ever discuss organ donation with your } \\
\text { loved one?) }\end{array}$ & $\begin{array}{l}\text { Requesters' approach is active (e.g., the overwhelming } \\
\text { majority of people in the United States support organ } \\
\text { donation and transplantation) }\end{array}$ \\
\hline $\begin{array}{l}\text { Requesters raise the possibility of donation } \\
\text { (e.g., We will support you in whatever } \\
\text { choice you make) }\end{array}$ & $\begin{array}{l}\text { Requesters are affirmative about donation (e.g., most } \\
\text { people, if given the chance to save a life, will do it) }\end{array}$ \\
\hline
\end{tabular}

